\title{
Mycological tests and onychomycosis
}

\author{
R. R. DAVIES \\ From the Wright-Fleming Institute of Microbiology, St Mary's Hospital Medical School, \\ London
}

SYNOPSIS The value of direct microscopy and cultural tests in onychomycosis is reported on the results of the examination of 3,955 nail collections from patients infected with Trichophyton rubrum. Of the total number of mycological diagnoses, $15 \%$ would have been missed if culture had been omitted and $53 \%$ if direct microscopy had not been undertaken.

\section{METHODS}

In the mycological diagnosis of onychomycosis tissue may be examined either by culture or by the so-called direct method, in which nail parings, after hydrolysis in potassium hydroxide solution, are squashed to a more or less unicellular layer and then searched microscopically for the presence of hyphae or mycelium. In some laboratories direct examination is performed only when no fungi have been grown within a period varying from three to six weeks from the planting of the nail in agar media; in others culture is undertaken only when direct examination has shown fungus to be present, and there are yet other laboratories performing both tests for every specimen.

In our routine for the investigation of nail parings, three or four pieces are examined in $30 \% \mathrm{KOH}$, three are planted in peptone glucose agar containing $40 \mu \mathrm{g} / \mathrm{ml}$ chloramphenicol, and six in malt extract agar containing $40 \mu \mathrm{g} / \mathrm{ml}$ chloramphenicol and $0.5 \mathrm{mg} / \mathrm{ml}$ of cycloheximide. All cultures are incubated at $25^{\circ} \mathrm{C}$ for six weeks before any are discarded as negative. No direct preparation is recorded as negative until it has been searched for a minimum of ten minutes unless the amount of material is inadequate.

This paper reports an analysis of the results of examining 3,955 samples of nails from patients with Trichophyton rubrum infections during a therapeutic trial of griseofulvin (Davies, Everall, and Hamilton, 1967).

\section{RESULTS}

Table I shows the relative numbers of mycological diagnoses by direct microscopy, culture, or both.

Only $913(46 \%)$ of the nails judged to be infected by such clinical criteria as hyperkeratosis and discoloration showed fungus by microscopy or culture or both (Table I). Had greater care been taken in collection and a greater amount tested from each

Received for publication 21 March 1968. nail, the figure might have been higher, but fungi are not the sole cause of nail dystrophy. On the other hand it is noteworthy that $170(9 \%)$ of the normal, healthy looking nails from infected patients showed fungus by one or other method.

\section{TABLE I}

NUMBER OF NAILS DEMONSTRATED TO BE INFECTED BY TWO DIFFERENT MYCOLOGICAL TESTS

\begin{tabular}{|c|c|c|c|c|c|}
\hline \multirow[t]{3}{*}{ Direct Microscopy } & \multicolumn{5}{|c|}{ Clinical Appearance } \\
\hline & \multicolumn{2}{|l|}{ Infected } & \multicolumn{2}{|l|}{ Normal } & \multirow[t]{2}{*}{ Totals } \\
\hline & Positive & Negative & Positive & Negative & \\
\hline $\begin{array}{l}\text { Culture positive } \\
\text { Culture negative }\end{array}$ & $\begin{array}{l}313 \\
490\end{array}$ & $\begin{array}{r}110 \\
1,088\end{array}$ & $\begin{array}{l}32 \\
79\end{array}$ & $\begin{array}{r}59 \\
1,784\end{array}$ & $\begin{array}{r}514 \\
3,441\end{array}$ \\
\hline Totals & 803 & 1,198 & 111 & 1,843 & 3,955 \\
\hline
\end{tabular}

Of 2,001 nails regarded as infected by the clinician, $803(40 \%)$ showed fungus by direct microscopy but in only $313(39 \%)$ of these was $T$. rubrum isolated. The difficulty in isolating fungus from nails is well recognized (Walshe and English, 1966) and the figure of $39 \%$ found here compares favourably with that of $23 \%$ recorded by Walshe and English. If the specimens had been examined by direct microscopy and the cultural tests omitted $12 \%$ of the mycologically confirmed infections would have been missed, whilst if cultural tests alone had been performed only $46 \%$ of the diagnoses would have been made.

Of 1,954 'clinically normal' nails, 170 contained fungus, $111(65 \%)$ showed fungus in direct microscopy, and $32(29 \%)$ of these yielded fungus in culture. Here, if direct microscopy had been undertaken and the cultural tests omitted, $35 \%$ of the infections would have been missed, whilst if the 
cultural tests alone had been performed, only $54 \%$ of the infections would have been observed.

Of the $\mathbf{4 2 3}$ diseased nails yielding fungus in culture, $313(74 \%)$ would also have been diagnosed microscopically; for the 91 healthy nails from which fungus was grown the proportion was $32(35 \%)$.

\section{DISCUSSION}

Strauss and Kligman (1957) in a study of athletes foot among the inmates of a penitentiary reported $2 \%$ of their diagnoses would have been missed if culture were omitted, and $23 \%$ if $\mathrm{KOH}$ examination were omitted. They do not report on nails alone and their 377 specimens appear to have included a significant number from skin. Here, in 3,955 samples from the nails of patients infected with $T$. rubrum, $15 \%$ of the total number of diagnoses would have been missed if culture had been omitted and $53 \%$ if direct microscopy had not been undertaken.

That the isolation of fungus in culture was more frequently accompanied by the observation of mycelium in direct examination in specimens from diseased, than in those from normal nails, may be explained by the fact that in collecting from a 'normal nail' parings are taken from the entire distal edge, whereas in a discoloured or hyperkeratotic nail they tend to be taken from the dystrophic area in which the fungus is likely to be concentrated.

Jillson and Piper (1957) in a histological study of fungus-infected nail found that the nail is composed of three layers: the dorsal nail, the main nail body or intermediate nail, and the deepest ventral nail. They concluded that $T$. rubrum infection initially involves the deep ventral nail to which its growth is largely confined but with, at times, extension into the intermediate layer. Since debris is collected between the digit and the ventral surface of the nail it seems reasonable to suggest that it is this area that first becomes infected. Thus early infection in the outgrowing nail is sampled if parings are taken across the entire free edge of the nail. In the dystrophic nail, where the fungus has penetrated deeply towards the $\mathrm{O}$ matrix, samples from the free edge of the nail may $\Rightarrow$ contain mycelium which is no longer viable, and this? would account for the fact that mycelium is oftene observed in specimens from which no fungus is grown.

Mycological tests frequently fail to confirm the clinical diagnosis of tinea. In longstanding infectionsen of the nail the fungus may be confined to the vicinity of the matrix, and consequently not sampled inparings taken from the free edge. In the collection of skin scrapings it is mainly the more disjunct parts of the corneum which are removed, and where theo stratum corneum is thick, as in the soles, the fungus may be confined to the deeper conjunct layers. कs

It must be concluded that in the mycological diagnosis of onychomycosis both direct microscopyo and cultural tests are essential and the practice of attempting to culture from tissue found to be in- $\vec{z}$ fected by direct examination only should beo abandoned. Where the amount of material received in the laboratory is insufficient for both tests, directo microscopy is to be preferred since it is the more likely to confirm the clinician's presumptive diag $\overrightarrow{0}$ nosis. Whilst the development of an identifiables colony of $T$. rubrum from nail parings usually requires a minimum of 14 days' incubation, the result of a direct test can be available within an hour of the specimen being collected.

I wish to thank Dr G. Mitchell-Heggs and $\mathrm{Dr} M \stackrel{\mathbb{Q}}{\stackrel{2}{2}}$ Feiwel of the Skin Department, St Mary's Hospital, ande Dr J. Everall of the Skin Department, Royal Marsden Hospital, for clinical material, Miss M. J. Denny for technical assistance, and the Imperial Chemical Industries? for financial assistance during the course of the work.

\section{REFERENCES} Davies, R. R.,

Jillson, O. F., and Piper, E. L. (1957). J. invest. Derm., 28, 137.

Strauss, J. S., and Kligman, A. M. (1957). Arch. Derm., 76, 70.

Walshe, M. M., and English, M. P. (1966). Brit. J. Derm., 78, 198. 